Polish Journal of Microbiology

2012, Vol. 61, No 4, 239-246

MINIREVIEW

\title{
The Controversy over Anti-Helicobacter pylori Therapy
}

\author{
KATARZYNA M. BOCIAN and ELŻBIETA K. JAGUSZTYN-KRYNICKA*
}

Department of Bacterial Genetics, Institute of Microbiology, Faculty of Biology,

University of Warsaw, Warsaw, Poland

Received 11 May 2012, revised 14 September 2012, accepted 18 September 2012

Abstract

Helicobacter pylori is a Gram-negative spiral-shaped bacterium, member of $\varepsilon$-Proteobacteria specifically colonizing the gastric epithelium of humans. It causes one of the most common infections worldwide, affecting about half of the world's population. However, it should be noted that the prevalence of $H$. pylori, particularly in the Western world, has significantly decreased coinciding with an increase of some autoimmune and allergic diseases, such as asthma. Various epidemiological studies have also documented a negative association between H. pylori colonization and the presence of GERD (gastroesophageal reflux disease) and risk of esophageal cancer. Additionally, an upward trend of obesity recently observed in inhabitants of developed countries raised a question about the relationship between $H$. pylori infection and the human body mass index. The first part of this review describes common, recommended anti- $H$. pylori treatments. The second part, presents the results of recent experiments aimed at evaluating the association between $H$. pylori infections and gastro-esophageal diseases, the level of stomach hormones, the human body mass index and allergic diseases. Although some studies suggest an inverse association of $H$. pylori infection with some health problems of the modern world such as asthma, obesity or GERD, H. pylori should be considered as a harmful human pathogen responsible for serious and sometimes lethal diseases. Thus, many scientists advocate the eradication of $H$. pylori.

Ke y w o rd s: Helicobacter pylori, allergy, GERD, NAP protein, obesity, therapy

\section{Introduction}

Helicobacter pylori is a Gram-negative spiral-shaped bacterium, belonging to $\varepsilon$-Proteobacteria, which specifically colonizes the gastric epithelium of humans causing one of the most common infection worldwide. It affects about half of the world's population; yet, its prevalence varies geographically. Currently, H. pylori infections are highly prevalent in developing countries, but are disappearing in developed countries. There are $40 \%$ of infected individuals in the general Polish population $(84 \%$ of the infected adult population) (Dzieniszewski and Jarosz, 2008). H. pylori infections induce both acute and chronic gastritis and peptic ulcers. It is also considered to be a high risk factor for the development of mucosa-associated lymphoid tissue lymphoma and adenocarcinoma of the stomach. Although most infected individuals have no symptoms, approximately $10-20 \%$ of cases of $H$. pylori infections will lead to development of peptic ulcers and approximately $1 \%$ to gastric cancer. Based on results of clinical studies, the World Health Organization has assigned $H$. pylori infections as class I carcinogens. There is sig- nificant evidence indicating that the bacterial genotype is the most important factor determining the type of induced pathology. Additional factors include host genotype and environmental aspects, such as nutrition.

Upon infection, $H$. pylori activates in epithelial cells multiple intracellular pathways, which affect various cellular functions. Many virulence factors produced by all or just some $H$. pylori clinical isolates are involved in the development of disease symptoms. Among them, the most extensively studied are various adhesins (involved in bacterial adhesion to gastric mucosal cells), ureases (which neutralize the acidic environment of the stomach), cytotoxin-associated gene A (CagA) protein and the CagA pathogenicity island (involved in interactions with many host signal-transduction pathways), vacuolating cytotoxin $\mathrm{A}$ (VacA, which modulates the host immune cell physiology), neutrophil-activating protein $\mathrm{A}(\mathrm{NapA})$ and products of genes located within "plasticity zone" such as duodenal ulcer promoting protein (DupA, which is a risk marker for development of duodenal ulcer and a protective factor against gastric cancer). It has recently been shown that H. pylori infections induce aberrant methylation in a number of gene

\footnotetext{
* Corresponding author: E.K. Jagusztyn-Krynicka, Department of Bacterial Genetics, Institute of Microbiology Faculty of Biology, University of Warsaw; Miecznikowa 1, 02-096, Warsaw, Poland; phone (4822) 5541216; fax (4822) 5541402; e-mail address: kjkryn@biol.uw.edu.pl
} 
promoters in gastric mucosa, which are known to be methylated in cancer patients (Cover and Blanke, 2005; Ding et al., 2010; Douraghi et al., 2008; Tegtmeyer et al., 2011; Yamaoka, 2008).

Sequencing of several $H$. pylori genomes and comparative genomics experiments revealed a high level of genome diversity. At first, by comparing the genomes of $15 \mathrm{H}$.pylori strains Salama et al. determined that H. pylori genes constituting the core set count 1281 genes (Salama et al., 2000). The growing number of genomes included in microarray analyses resulted in redefining the number of core genes in $H$.pylori genomes. At present, it is widely assumed that $H$. pylori core genes consist of about 1100 genes. Auxiliary genes amount to $22-27 \%$ of the genome, encoding mainly proteins of unknown function, the Cag protein, outermembrane proteins (OMP) and proteins involved in DNA metabolism (Dong et al., 2009; Gressmann et al., 2005). Some strain-specific genes are disease-specific. The diversity of $H$. pylori genomes is not only noticeable when evaluating the number of common genes, but also when examining gene nucleotide sequences. Genetic variety among $H$. pylori strains arises from intra-genomic diversifications (for example - point mutations, recombination and slipped-strand mispairing) as well as inter-genomic recombination - the ability of $H$. pylori to take up exogenous DNA and incorporate it into its genome (Dorer et al., 2009). The process allows the pathogen to adapt to various niches within the same host or to the changing environments during long-lasting infections.

\section{Recommended anti-Helicobacter therapies}

According to several international guidelines, different drug regimens are recommended for treatment of $H$. pylori infections. These include triple, quadruple, (sequential or concomitant) therapy regimens. Treatment regimen should be selected according to areas of low or high claritromycin resistance. Standard triple therapy which involves administration of a proton pump inhibitor combined with clarithromycin and amoxicillin or metronidazol for 7 to 14 days was the most commonly recommended first-line treatment by guidelines published in Europe and North America since the mid 1990s (Chey and Wong, 2007; Malfertheiner et al., 2012). However, the recent data showed that this drug combination has lost some efficacy and according to recently published worldwide guidelines should be abandoned when the clarithromycin resistance rate in the region is more than $15-20 \%$ (Malfertheiner et al., 2012). Increased doses of proton pump inhibitors had small effects on eradication rates (Fuccio et al., 2007; Vakil and Connor, 2005). Bismuth- based quadruple and levofloxacin-based triple regimens are also frequently recommended, but as second-line therapies. Third-line options (empiric regimes tailored to individual antibiotic sensitivities) include treatments based on rifabutin (an antituberculous agent) and furazolidone. However, susceptibility testing is not common, but, when it is employed, it is only carried out in specialist research-oriented centers. Sequential therapy is an alternative to standard triple therapy for eradication of H.pylori (Gisbert, 2010; Gisbert et al., 2010). It aims to overcome clarithromycin resistance. During the first stage of therapy, amoxicillin is administered to weaken the bacterial cell wall, which otherwise prevents the formation of channels that block clarithromycin from entering the bacterial cell and, in effect, cause resistance to the antibiotic. Subsequently, clarithromycin and nitroimidazole are administered for a further 5 days in the second phase of the therapy. Administration of the proton-pump inhibitor is continuously employed throughout the treatment. Generally, the sequential therapy has a better rate of curing $H$. pylori infection than classical triple therapy. However, clinically the sequential administration of the two drug combinations is relatively complex. As an alternative the concomitant quadruple therapy including the same four drugs as sequential therapy given concomitantly has been tested. It appears to be equally effective as sequential therapy but less complex (Essa et al., 2009; Wu et al., 2010).

Treatment against $H$. pylori still fails in more than $20 \%$ of patients and a more acceptable eradication level is greatly anticipated. Two main obstacles against effective therapy are the resistance of $H$. pylori to different antibiotics (i.e. clarithromycin, metronidazole, amoxicillin, levofloxacin), correlated with the consumption of antibiotics in the general population, and lack of strict abidance to the rules of drug administration, which involves the efforts of both doctor and patient. The prescribed defined therapy is long and complicated. It is uncomfortable for patients and impedes complying with the recommended procedures. In view of these facts, there is an urgent need to intensify the fight against $H$. pylori by developing alternative methods of treating Helicobacter pylori infections (De Francesco et al., 2010; O'Connor et al., 2010). It was documented that the addition of probiotics to a standard antibiotic treatment improved slightly $H$. pylori eradication rate and considerably reduced therapy-associated adverse effects (Lionetti et al., 2010; Vitor and Vale, 2011; Zou et al., 2009).

The alarming rise of antibiotic resistant pathogenic microorganisms renewed interest in antibacterial, including anti-Helicobacter, research and forced scientists to search for new drugs with novel modes of action. Some new anti-Helicobacter drugs are currently under 
development. New, potentially effective agents should fulfill several requirements, at least display strong, specific antibacterial activity against Helicobacter, when used in mono-therapy, and exhibit activity in low $\mathrm{pH}$. Examples of such agents are: the TG44 molecule synthesized by the Nagase ChemeteX Corporation and acyl-lysyl oligomers (OAKs). The former compound, tested so far only in in vitro experiments, is a highly specific anti-Helicobacter molecule, which activity is based on the disruption of the cell outer membrane (Kamoda et al., 2006). Latter compounds are synthetic antimicrobial peptides (AMPs) of broad specificity, which demonstrate high efficacy against Helicobacter in in vitro and in vivo tests (Makobongo et al., 2009; Makobongo et al., 2012). They are a unique and diverse group of molecules produced by many tissues and cell types of various organisms. As AMPs have recently elicited interest as new antibacterial drugs, one can expect that new AMPs will be tested as anti-Helicobacter agents soon (Brogden, 2005). However, it should be kept in mind that AMP therapy might potentially enable pathogens to overcome the innate immune response of an immunocompetent host (Brodsky and Gunn, 2005).

\section{Unexpected consequences of Helicobacter pylori infection/eradication}

Impact of Helicobacter pylori infection on esophageal diseases. Symptoms of the gastro-esophageal reflux disease (GERD) appear when the impairment of motility of the gastric system allows for the contact of the gastric content with the esophagus epithelium. This may lead to development of Barrett esophagus (BE), which is recognized as a risk factor for the subsequent development of esophageal adenocarcinoma (EAC). The pathogenesis of these diseases is complex and multifactorial, but acidity of the refluxate is a crucial factor inducing GERD development.

The decreasing prevalence of $H$. pylori infections and related diseases, especially in developed countries, and, at the same time, an increase in the recognition of gastro-esophagal reflux symptoms and its complications, raise a question whether H.pylori is a likely etiological factor for this changing epidemiology. This phenomenon has been observed in many countries, at different geographic locations, such as Japan or USA (Blaser, 2008; Kim et al., 2011; Rajendra, 2011; Yang et al., 2009). The causal relationship between $H$.pylori infections and the gastro-esophageal disease has been examined in a large number of epidemiological studies. The first observations were made by Labenz et al., who reported that $H$. pylori eradication in patients with duodenal peptic ulcer stimulates the development of reflux eosophagitis (Labenz et al., 1997). Comparative analyses concentrated on assessing the rate of $H$. pylori infection in patients with reflux esophagitis compared to those with a normal esophagus as well as on the evaluation of the effect of $H$. pylori eradication on the development of reflux esophagitis. Although some studies confirmed the inverse associations between these two analyzed phenomena, contradictory results also have been reported. For more details we recommended review papers, such as by Graham et al., 2007; Hung and Wong, 2009; Sharma and Vakil, 2003; Souza and Lima, 2009. Lack of consensus between various studies may be due to many factors, such as difficulties in evaluating the clinical aspects of $H$. pylori infection or the differences in the genotype of the infecting strain. It was documented that $H$. pylori can colonize various parts of the stomach and that the site of infection is an important factor influencing the consequences of colonization. Antrum gastritis is related to high inflammation and high acid secretion, whereas corpus gastritis correlates with low acid secretion. Another important factor is the genetic and immunological status of the host. Three recent meta-analysis studies conducted by Islami and Kamangan, Qian et al. and Yaghoobi et al. summarized the data published during last twenty years (Islami and Kamangar, 2008; Qian et al., 2011; Yaghoobi et al., 2010) Islami and Kamangar used 19 carefully selected studies to examine the association between $H$. pylori infection and esophageal adenocarcinoma (EAC). Presented data suggested inverse association of the CagA-positive H. pylori colonization with risk of EAC. Meta-analysis of Yaghoobi et al. evaluated the risk of GERD development due to $H$. pylori eradication and showed that the frequency of GERD does not increase after H.pylori eradication among dyspeptic patients, whereas a two-fold higher risk of GERD development in patients with peptic ulcers was observed. Meta-analysis conducted by Qian et al. did not show any association between $H$. pylori eradication and the occurrence of symptomatic GERD. Potential mechanism of the protective effect of $H$. pylori gastric colonization against esophageal diseases still remains unexplainable. Apart from changes in gastric acidity, stomach colonization by $H$. pylori influences the level of at least two hormones: leptin and ghrelin (see below), which can influence the esophagus epithelium as esophagus cells contain leptin receptors. The recent progress in sequencing technology in combination with the development of new bioinformatic tools allows us to study the microbiome (a set of bacterial genes present in a specific ecological niche) of the stomach and esophagus. It is expected that this strategy will permit tracing changes in the microbiome that are correlated with disease development or are due to $H$. pylori eradication. Analysis of the stomach microbiota revealed that it is much more complex than it was assessed before. $H$. pylori was found to be 
the most abundant phylotype in the stomach of individuals tested as $H$. pylori-positive by standard methods (Bik et al., 2006). Structure of the human gastric bacterial community was determined to be dependent on the $H$. pylori-induced disease. For instance, the stomach microbiota of gastric cancer patients differs significantly compared to microbiota of dyspeptic individuals (Dicksved et al., 2009; Maldonado-Contreras etal., 2011). Metagenomic study of the esophagal microbiome also revealed its astonishing complexity and significant changes in the microbiome structure connected to pathological alterations of the esophageal epithelium (Yang et al., 2009). As even short term antibiotic treatment of $H$. pylori infections has tremendous repercussions for the gut microbiome structure, it may also be a factor of GERD development (Jakobsson et al., 2010). Further metagenomic studies are required to shed more light on the contribution of stomach or esophagus dysbiosis on disease development.

Correlation between Helicobacter pylori infection and asthma and allergic diseases. In recent years, a rise in the prevalence of bronchial asthma in developed countries has been observed. Many environmental factors, such as tobacco smoke, air pollution or allergen exposure, are without doubt responsible for this documented upward tendency. However, the influence of human microbiota on allergic diseases should be also taken into account. As over the past years the prevalence of $H$. pylori infection has been decreasing, the causal relationship between $H$. pylori infection and asthma was carefully evaluated in many epidemiological studies. The relationship between these two diseases was noted for the first time in 1997 by Kosunen et al. (Kosunen et al., 1997). Although the conducted studies provided controversial results, it is rather accepted that human colonization with $H$. pylori CagA-positive strains may have an inverse effect on development of bronchial asthma. However more studies are required to prove a real association between $H$. pylori eradication in childhood and subsequent development of asthma (Hung and Wong, 2009). At this point it should be also pointed out that $H$. pylori CagA positive strains which potentially may be protective against GERD or asthma are strongly associated with gastric cancer, which is the second leading cause of cancer-related deaths worldwide (Huang and Hunt, 2003).

For more data from epidemiological studies see papers cited by Roussos et al., D'Elios et al. and Malferheiner et al. (D'Elios et al., 2009; Malfertheiner et al., 2011; Roussos et al., 2005).

Despite the lack of a clear hypothesis explaining the link between these two diseases, some data suggest that this inverse association might be due to the differences in the type of immune response induced.
According to the WHO definition, asthma is a chronic inflammatory disease of the airways associated with a predominant activation of CD4+ Th2 lymphocytes, which produce several Th2 cytokines, including IL-4 and IL-5 (Del Prete et al., 1993; Robinson et al., 1992).

In contrast, H. pylori gastric colonization preferentially elicits a Th1 mucosal immune response with the production of IFN- $\gamma$, IL-12, IL-18, IL-23 and TNF- $\alpha$ (D'Elios et al., 2009). H.pylori neutrophil-activating protein (HP-NAP) is a main $H$. pylori virulence factor responsible for this effect. HP-NAP is a $200 \mathrm{kDa}$ ballshaped dodecamer formed by four-helix bundled subunits $(17 \mathrm{kDa})$ with a hollow central part (Tsuruta et al., 2012). Structurally it belongs to the Dps (DNA protecting protein under starved condition) protein family. The role of this protein in bacterial cells is still controversial. Analysis of its ability to bind to DNA resulted in incoherent data. Additionally, although HP-NAP is a bacterioferritin able to bind up to 500 atoms of iron per dodecamer, the role of this process in bacterial physiology remains unclear. Furthermore, HP-NAP was described as a cytoplasmic protein, released after cell lysis. Once released in the gastroduodenal mucosa, NAP is transported via transcytosis across endothelial cells, (de Bernard and D'Elios, 2010) stimulating subsequently human neutrophils, monocytes and dendritic cells via activation of the Toll-like receptor 2 (TLR2). In consequence, high upregulation of both the production of IL-12 and IL-23 occurs (D'Elios and de Bernard, 2010). HP-NAP activity also causes the decrease of IL-4-secreting cells. As a result, HP-NAP supported by other H.pylori factors induces the production of IL-12 and IL-23 that both promote the preferential development of Th- 1 cells and repress the Th-2 allergic response (Amedei et al., 2010; Amedei et al., 2006; Cappon et al., 2010). Administration of HP-NAP has a beneficial effect in case of asthma. Arnold et al. proved that $H$. pylori infections induced $\mathrm{T}$ regulatory cells (Tregs) and protected mice from asthma, especially when mice were infected neonatally. After H.pylori eradication due to antibiotic treatment, the protection effect was abolished (Arnold et al., 2011). The efficacy of HP-NAP against asthma was also confirmed by D'Elios et al., who documented that systemic and mucosal administrations of HP-NAP result in reduction of the amount of eosinophil cells, immunoglobulin E and Th2 cytokines in the mice bronchitis model. This suggests that $H$.pylori infection is able to induce long lasting Th1 type of immune response. Taking the above into account, HP-NAP seems to be an effective factor for prevention and treatment of asthma and allergic diseases (D'Elios et al., 2009).

Apart from playing a role in induction of Th1 inflammation and inhibition of the Th2 response, HP-NAP may potentially be used in cancer therapy. As a very 
powerful inducer of IL-12 and IL-23, HP-NAP represent the most effective cytokine in regard to tumor eradication, anti-metastatic activity and long-term anti-tumor immunity (Colombo and Trinchieri, 2002). IL-12 was recently ranked third in a comprehensive list of immunotherapeutic agents with high potential in treating cancer. Codolo and colleagues showed that local administration of HP-NAP decreases tumor growth by triggering tumor necrosis in a mouse model of bladder cancer. HP-NAP-treated tumors show also a reduced vascularization due to the anti-angiogenic activity of IFN- $\gamma$ induced by treatment of cancer implants with HP-NAP (Codolo et al., 2012a; Codolo et al., 2012b). In sum it should be pointed out that even persistent infection with $H$.pylori may be linked to protection from some autoimmune diseases, it is not recommended to leave $H$. pylori infection untreated in asthmatic patients. (D'Elios and de Bernard, 2010). However based on the performed studies it is tempted to speculate that administration of rHP-NAP might be beneficial not only against allergic diseases, but also to fight cancer.

Impact of H.pylori infection and anti-Helicobacter therapy on obesity. The decreasing prevalence of $H$. pylori infections during the second half of the $20^{\text {th }}$ century and the beginning of the $21^{\text {th }}$ is noticeable across the whole developed world. For example, in some countries currently less than $10 \%$ of school children are carriers of this microorganism (Chen and Blaser, 2008; Rothenbacher et al., 1998; Segal et al., 2008). At the same time, the incidence of obesity among the same population group has been observed. It prompts many research groups to evaluate the impact of $H$. pylori infection on body weight.

Two hormones, leptin and ghrelin, play a crucial role in body weight balance by regulating food intake and energy disbursement. Leptin is a $16 \mathrm{kDa}$ protein, the product of the $o b$ gene, which is synthesized and secreted mainly by adipocytes (Zhang et al., 1994). However, it has recently been shown that this hormone is also present in rat and human gastric mucosa (Bado et al., 1998; Sobhani et al., 2000). As leptin deficiency causes obesity in humans and mice and since $H$. pylori induced gastritis may influence the leptin level, many comparative epidemiological studies have recently been conducted to examine the effect of $H$. pylori infections on gastric leptin expression and on the body mass index (BMI). Most of these studies compared infected and non-infected individuals by CagA-positive and CagAnegative strains. Infection by CagA-positive $H$. pylori strains was shown to result in more severe gastritis and more often led to gastric cancer than infection by CagA-negative $H$. pylori. Majority of obtained data has not implied any associations between the plasma leptin level and H. pylori infection (Azuma et al., 2001; Chuang et al., 2009; Ioannou et al., 2005). However, a study examining prepubertal children conducted by Pacifico et al. indicated that the serum leptin level was significantly lower in $H$. pylori positive patients than in $H$. pylori negative individuals (Pacifico et al., 2008). In contrast to data concerning the plasma leptin level, many investigators provided convincing results showing that $H$. pylori infection results in a significant increase of gastric leptin expression (Azuma et al., 2001; Jun et al., 2007) what, in turn, might led to weight loss.

Conflicting results have also been published regarding the effect of H. pylori infection on ghrelin level. Ghrelin is a 28 amino acid peptide predominantly produced by the stomach, which is thought to be the most potent growth hormone releaser (Kojima et al., 1999). Ghrelin has also been implicated in the control of food intake (Nakazato et al., 2001). It was determined to affect metabolic functions and evoke weight gain (Wren et al., 2001). In the study performed by Gokcel et al., no differences in the plasma ghrelin concentration between adults positive and negative for $H$. pylori have been observed (Gokcel et al., 2003). In contrast, many studies performed on Japanese patients revealed a strong negative impact of $H$. pylori infection on the plasma ghrelin level, which was positively correlated with gastric ghrelin mRNA expression (Isomoto et al., 2005a; Isomoto et al., 2005b; Shiotani etal., 2005). Additionally, some analyses indicated that this effect is dependent on the severity of the disease and influenced by the patient's gender (Chuang et al., 2009).

Although $H$. pylori infection modulates the plasma ghrelin and stomach leptin level, epidemiological studies do not document any associations between $H$. pylori infection and the body max index of the analyzed patients. A large US-based population study showed that there is no correlation between the presence of $H$. pylori and the genetic status of the colonizing strain (CagA-positive vs. CagA-negative strains) as well as the weight of the analyzed individual (Cho et al., 2005; Ioannou et al., 2005).

The second set of experiments was directed towards analyzing the effect of $H$.pylori eradication, plasma leptin or ghrelin level and the increase in BMI. They provided rather consistent results. In many studies, it has been reported that $H$. pylori eradication is associated with the increase of the circulating leptin level, the decrease of the ghrelin level resulting in an increase in BMI. This effect was independent of the examined population and was observed both among adult Japanese as well as American individuals who underwent antiHelicobacter therapy. Additionally, similar long-term effect of $H$. pylori eradication was observed among prepubertal children (Francois et al., 2011; Fujiwara et al., 2002; Osawa et al., 2006; Pacifico et al., 2008). However, 
Suto et al. noticed that the effect of $H$. pylori eradication on $\mathrm{BMI}$ is dependent on the serum pepsinogen $\mathrm{I} / \mathrm{II}$ ratio (Suto et al., 2009). Interestingly, experiments conducted by Nwokolo et al., who for the first time examined the effect of $H$. pylori eradication in $H$. pylori asymptomatic patients, showed a significant increase of the ghrelin level after therapy. Authors have thus concluded that lowering the prevalence of $H$. pylori infections in developed countries might lead to the observed increase in obesity (Nwokolo et al., 2003).

\section{Summary}

Collectively, it is obvious that the decreased H. pylori prevalence among populations of Western countries could lead to significant changes in human health. However, the plausible mechanism is extremely complex as it is influenced not only by the genotype of the pathogen, but also by the immunological and genetic status of the host. As $H$. pylori infection is almost always acquired during childhood, the microorganism is able to alter the resident stomach microbiota over a years, what leads to other pathologies such as EAC. Thus eradication of $H$. pylori can also stop transmission to healthy persons and prevent other pathologies connected with stomach microbiota changes.

Helicobacter pylori has accompanied humans since the dawn of time and coevolved together with its host. Thus, it is not surprising that the interrelation between the microorganism and its host is complex - the bacterium behaves as a pathogen causing some severe diseases, such as the peptic ulcer disease or gastric cancer, while, at the same time, as a commensal protecting from other infections. According to dr M. Blaser, gastroenterologists should re-think recommendations for H. pylori therapy and decide under what conditions such infections should be eradicated. We will be faced with the necessity of deciding how to react when human $H$. pylori infection is not so prevalent. Evidences collected so far indicate that the benefits of eradication of $H$. pylori outweigh the risks. H. pylori CagA positive strains which potentially may be protective against GERD or asthma are strongly associated with gastric cancer, which is the second leading cause of cancerrelated deaths worldwide.

\section{Literature}

Amedei A., G. Codolo, G. Del Prete, M. de Bernard and M.M. D'Elios. 2010. The effect of Helicobacter pylori on asthma and allergy. J. Asthma Allergy 3: 139-147.

Amedei A., A. Cappon, G. Codolo, A. Cabrelle, A. Polenghi, M. Benagiano, E. Tasca, A. Azzurri, M.M. D’Elios, G. Del Prete and others. 2006. The neutrophil-activating protein of Helico- bacter pylori promotes Th1 immune responses. J. Clin. Invest. 116: 1092-1101.

Arnold I.C., N. Dehzad, S. Reuter, H. Martin, B. Becher, C. Taube and A. Muller. 2011. Helicobacter pylori infection prevents allergic asthma in mouse models through the induction of regulatory T cells. J. Clin. Invest. 121: 3088-3093.

Azuma T., H. Suto, Y. Ito, M. Ohtani, M. Dojo, M. Kuriyama and T. Kato. 2001. Gastric leptin and Helicobacter pylori infection. Gut 49: 324-329.

Bado A., S. Levasseur, S. Attoub, S. Kermorgant, J.P. Laigneau, M.N. Bortoluzzi, L. Moizo, T. Lehy, M. Guerre-Millo, Y. Le Marchand-Brustel and others. 1998. The stomach is a source of leptin. Nature 394: 790-793.

Bik E.M., P.B. Eckburg, S.R. Gill, K.E. Nelson, E.A. Purdom, F. Francois, G. Perez-Perez, M.J. Blaser and D.A. Relman. 2006. Molecular analysis of the bacterial microbiota in the human stomach. Proc. Natl. Acad. Sci. USA, 103: 732-737.

Blaser M.J. 2008. Disappearing microbiota: Helicobacter pylori protection against esophageal adenocarcinoma. Cancer Prev. Res. (Phila) 1: 308-311.

Brodsky I.E. and J.S. Gunn. 2005. A bacterial sensory system that activates resistance to innate immune defenses: potential targets for antimicrobial therapeutics. Mol. Interv. 5: 335-337.

Brogden K.A. 2005. Antimicrobial peptides: pore formers or metabolic inhibitors in bacteria? Nat. Rev. Microbiol. 3: 238-250.

Cappon A., C. Babolin, D. Segat, L. Cancian, A. Amedei, F. Calzetti, M.A. Cassatella, M.M. D'Elios and M. de Bernard. 2010. Helicobacter pylori-derived neutrophil-activating protein increases the lifespan of monocytes and neutrophils. Cell Microbiol. 12: 754-764.

Chen Y. and M.J. Blaser. 2008. Helicobacter pylori colonization is inversely associated with childhood asthma. J. Infect. Dis. 198: 553-560.

Chey W.D. and B.C. Wong. 2007. American College of Gastroenterology guideline on the management of Helicobacter pylori infection. Am. J. Gastroenterol. 102: 1808-1825.

Cho I., M.J. Blaser, F. Francois, J.P. Mathew, X.Y. Ye, J.D. Goldberg and E.J. Bini. 2005. Helicobacter pylori and overweight status in the United States: data from the Third National Health and Nutrition Examination Survey. Am. J. Epidemiol. 162: 579-584.

Chuang C.H., B.S. Sheu, H.B. Yang, S.C. Lee, A.W. Kao, H.C. Cheng, W.L. Chang and W.J. Yao. 2009. Gender difference of circulating ghrelin and leptin concentrations in chronic Helicobacter pylori infection. Helicobacter 14: 54-60.

Codolo G., M. Fassan, M.M. D'Elios and M. de Bernard. 2012a. HP-NAP new therapy for bladder cancer: numquam periculum sine periculo vincitur. Cancer Immunol. Immunother. 61: 447-448.

Codolo G., M. Fassan, F. Munari, A. Volpe, P. Bassi, M. Rugge, F. Pagano, M.M. D'Elios and M. Bernard. 2012b. HP-NAP inhibits the growth of bladder cancer in mice by activating a cytotoxic Th1 response. Cancer Immunol. Immunother. 61: 31-40.

Colombo M.P. and G. Trinchieri. 2002. Interleukin-12 in antitumor immunity and immunotherapy. Cytokine Growth Factor Rev. 13: $155-168$.

Cover T.L. and S.R. Blanke. 2005. Helicobacter pylori VacA, a paradigm for toxin multifunctionality. Nat. Rev. Microbiol. 3: 320-332. D'Elios M.M. and M. de Bernard. 2010. To treat ornot to treat Helicobacter pylori to benefit asthma patients. Expert Rev. Respir. Med. 4: 147-150.

D'Elios M.M., G. Codolo, A. Amedei, P. Mazzi, G. Berton, G. Zanotti, G. Del Prete and M. de Bernard. 2009. Helicobacter pylori, asthma and allergy. FEMS Immunol. Med. Microbiol. 56: 1-8. de Bernard M. and M.M. D'Elios. 2010. The immune modulating activity of the Helicobacter pylori HP-NAP: Friend or foe? Toxicon 56: $1186-1192$. 
De Francesco V., A. Zullo, E. Ierardi, F. Giorgio, F. Perna, C. Hassan, S. Morini, C. Panella and D. Vaira. 2010. Phenotypic and genotypic Helicobacter pylori clarithromycin resistance and therapeutic outcome: benefits and limits. J. Antimicrob. Chemother. 65: 327-332. Del Prete G.F., M. De Carli, M.M. D'Elios, P. Maestrelli, M. Ricci, L. Fabbri and S. Romagnani. 1993. Allergen exposure induces the activation of allergen-specific Th2 cells in the airway mucosa of patients with allergic respiratory disorders. Eur. J. Immunol. 23: 1445-1449.

Dicksved J., M. Lindberg, M. Rosenquist, H. Enroth, J.K. Jansson and L. Engstrand. 2009. Molecular characterization of the stomach microbiota in patients with gastric cancer and in controls. J. Med. Microbiol. 58: 509-516.

Ding S.Z., J.B. Goldberg and M. Hatakeyama. 2010. Helicobacter pylori infection, oncogenic pathways and epigenetic mechanisms in gastric carcinogenesis. Future Oncol. 6: 851-862.

Dong Q.J., Q. Wang, Y.N. Xin, N. Li and S.Y. Xuan. 2009. Comparative genomics of Helicobacter pylori. World J. Gastroenterol. 15: 3984-3991.

Dorer M.S., S. Talarico and N.R. Salama. 2009. Helicobacter pylori's unconventional role in health and disease. PLoS Pathog. 5: e1000544. Douraghi M., M. Mohammadi, A. Oghalaie, A. Abdirad, M.A. Mohagheghi, M.E. Hosseini, H. Zeraati, A. Ghasemi, M. Esmaieli and N. Mohajerani. 2008. dupA as a risk determinant in Helicobacter pylori infection. J. Med. Microbiol. 57: 554-562. Dzieniszewski J. and M. Jarosz. 2008. Estimations of PTG-E for treatments in Helicobacter pylori infections - consensus 2008 (in Polish). Gastroenterologia Polska 15: 323-331.

Essa A.S., J.R. Kramer, D.Y. Graham and G. Treiber. 2009. Metaanalysis: four-drug, three-antibiotic, non-bismuth-containing "concomitant therapy" versus triple therapy for Helicobacter pylori eradication. Helicobacter 14: 109-118.

Francois F., J. Roper, N. Joseph, Z. Pei, A. Chhada, J.R. Shak, A. Z. de Perez, G. I. Perez-Perez and M. J. Blaser. 2011. The effect of $H$. pylori eradication on meal-associated changes in plasma ghrelin and leptin. BMC Gastroenterol. 11: 37.

Fuccio L., M. E. Minardi, R. M. Zagari, D. Grilli, N. Magrini and F. Bazzoli. 2007. Meta-analysis: duration of first-line proton-pump inhibitor based triple therapy for Helicobacter pylori eradication. Ann. Intern. Med. 147: 553-562.

Fujiwara Y., K. Higuchi, U.A. Arafa, T. Uchida, K. Tominaga, T. Watanabe and T. Arakawa. 2002. Long-term effect of Helicobacter pylori eradication on quality of life, body mass index, and newly developed diseases in Japanese patients with peptic ulcer disease. Hepatogastroenterology 49: 1298-1302.

Gisbert J.P. 2010. Sequential or concomitant therapy for Helicobacter pylori eradication? J. Clin. Gastroenterol.

Gisbert J.P., X. Calvet, A. O'Connor, F. Megraud and C.A. O'Morain. 2010. Sequential therapy for Helicobacter pylori eradication: a critical review. J. Clin. Gastroenterol. 44: 313-325.

Gokcel A., Y. Gumurdulu, F. Kayaselcuk, E. Serin, B. Ozer, A.K. Ozsahin and N. Guvener. 2003. Helicobacter pylori has no effect on plasma ghrelin levels. Eur. J. Endocrinol. 148: 423-426. Graham D.Y., Y. Yamaoka and H.M. Malaty. 2007. Contemplating the future without Helicobacter pylori and the dire consequences hypothesis. Helicobacter 12 Suppl 2: 64-68.

Gressmann H., B. Linz, R. Ghai, K.P. Pleissner, R. Schlapbach, Y. Yamaoka, C. Kraft, S. Suerbaum, T.F. Meyer and M. Achtman. 2005. Gain and loss of multiple genes during the evolution of Helicobacter pylori. PLoS Genet. 1: e43.

Huang J.Q. and R.H. Hunt. 2003. The evolving epidemiology of Helicobacter pylori infection and gastric cancer. Can. J. Gastroenterol. 17 Suppl B: 18B-20B.

Hung I.F. and B.C. Wong. 2009. Assessing the risks and benefits of treating Helicobacter pylori infection. Therap. Adv. Gastroenterol. 2: 141-147.
Ioannou G.N., N.S. Weiss and D.J. Kearney. 2005. Is Helicobacter pylori seropositivity related to body mass index in the United States? Aliment. Pharmacol. Ther. 21: 765-772.

Islami F. and F. Kamangar. 2008. Helicobacter pylori and esophagea cancer risk: a meta-analysis. Cancer Prev. Res. (Phila) 1: 329-338.

Isomoto H., Y. Nishi, K. Ohnita, Y. Mizuta, S. Kohno, H. Ueno and M. Nakazato. 2005a. The relationship between plasma and gastric ghrelin levels and strain diversity in Helicobacter pylori virulence. Am. J. Gastroenterol. 100: 1425-1427.

Isomoto H., H. Ueno, V.A. Saenko, M.S. Mondal, Y. Nishi, N. Kawano, K. Ohnita, Y. Mizuta, A. Ohtsuru, S. Yamashita and others. 2005b. Impact of Helicobacter pylori infection on gastric and plasma ghrelin dynamics in humans. Am. J. Gastroenterol. 100: 1711-1720.

Jakobsson H.E., C. Jernberg, A.F. Andersson, M. Sjolund-Karlsson, J.K. Jansson and L. Engstrand. 2010. Short-term antibiotic treatment has differing long-term impacts on the human throat and gut microbiome. PLoS One 5: e9836.

Jun D.W., O.Y. Lee, Y.Y. Lee, H.S. Choi, T.H. Kim and B.C. Yoon. 2007. Correlation between gastrointestinal symptoms and gastric leptin and ghrelin expression in patients with gastritis. Dig. Dis. Sci. 52: 2866-2872.

Kamoda O., K. Anzai, J. Mizoguchi, M. Shiojiri, T. Yanagi, T. Nishino and S. Kamiya. 2006. In vitro activity of a novel antimicrobial agent, TG44, for treatment of Helicobacter pylori infection. Antimicrob. Agents Chemother. 50: 3062-3069.

Kim N., S.W. Lee, J.I. Kim, G.H. Baik, S.J. Kim, G.S. Seo, H.J. Oh, S.W. Kim, H. Jeong, S.J. Hong and others. 2011. Effect of Helicobacter pylori eradication on the development of reflux esophagitis and gastroesophageal reflux symptoms: a nationwide multi-center prospective study. Gut Liver 5: 437-446.

Kojima M., H. Hosoda, Y. Date, M. Nakazato, H. Matsuo and K. Kangawa. 1999. Ghrelin is a growth-hormone-releasing acylated peptide from stomach. Nature 402: 656-660.

Kosunen T.U., A. Aromaa, P. Knekt, A. Salomaa, H. Rautelin, P. Lohi and O.P. Heinonen. 1997. Helicobacter antibodies in 1973 and 1994 in the adult population of Vammala, Finland. Epidemiol. Infect. 119: 29-34.

Labenz J., A.L. Blum, E. Bayerdorffer, A. Meining, M. Stolte and G. Borsch. 1997. Curing Helicobacter pylori infection in patients with duodenal ulcer may provoke reflux esophagitis. Gastroenterology 112: 1442-1447.

Lionetti E., F. Indrio, L. Pavone, G. Borrelli, L. Cavallo and R. Francavilla. 2010. Role of probiotics in pediatric patients with Helicobacter pylori infection: a comprehensive review of the literature. Helicobacter 15: 79-87.

Makobongo M.O., T. Kovachi, H. Gancz, A. Mor and D.S. Merrell. 2009. In vitro antibacterial activity of acyl-lysyl oligomers against Helicobacter pylori. Antimicrob. Agents Chemother. 53: 4231-4239. Makobongo M.O., H. Gancz, B.M. Carpenter, D.P. McDaniel and D.S. Merrell. 2012. The oligo-acyl lysyl antimicrobial peptide CK-2beta exhibits a dual mechanism of action and demonstrates strong in vivo efficacy against Helicobacter pylori. Antimicrob. Agents Chemother. 56: 378-390.

Maldonado-Contreras A., K.C. Goldfarb, F. Godoy-Vitorino, U. Karaoz, M. Contreras, M.J. Blaser, E.L. Brodie and M.G. Dominguez-Bello. 2011. Structure of the human gastric bacterial community in relation to Helicobacter pylori status. ISME J. 5: 574-579. Malfertheiner M.V., A. Kandulski, J. Schreiber and P. Malfertheiner. 2011. Helicobacter pylori infection and the respiratory system: a systematic review of the literature. Digestion 84: 212-220.

Malfertheiner P., F. Megraud, C.A. O’Morain, J. Atherton, A.T. Axon, F. Bazzoli, G.F. Gensini, J.P. Gisbert, D.Y. Graham, T. Rokkas and others. 2012. Management of Helicobacter pylori infection - the Maastricht IV/ Florence Consensus Report. Gut 61: 646-664. 
Nakazato M., N. Murakami, Y. Date, M. Kojima, H. Matsuo, K. Kangawa and S. Matsukura. 2001. A role for ghrelin in the central regulation of feeding. Nature 409: 194-198.

Nwokolo C.U., D.A. Freshwater, P. O'Hare and H.S. Randeva. 2003. Plasma ghrelin following cure of Helicobacter pylori. Gut 52: 637-640.

O'Connor A., J.P. Gisbert, D. McNamara and C. O'Morain. 2010 Treatment of Helicobacter pylori infection 2010. Helicobacter 15 Suppl 1: 46-52.

Osawa H., H. Kita, H. Ohnishi, M. Nakazato, Y. Date, C.L. Bowlus, Y. Ishino, E. Watanabe, T. Shiiya, H. Ueno and others. 2006 Changes in plasma ghrelin levels, gastric ghrelin production, and body weight after Helicobacter pylori cure. J. Gastroenterol. 41: 954-961.

Pacifico L., C. Anania, J.F. Osborn, E. Ferrara, E. Schiavo, M. Bonamico and C. Chiesa. 2008. Long-term effects of Helicobacter pylori eradication on circulating ghrelin and leptin concentrations and body composition in prepubertal children. Eur. J. Endocrinol. 158: 323-332.

Qian B., S. Ma, L. Shang, J. Qian and G. Zhang. 2011. Effects of Helicobacter pylori eradication on gastroesophageal reflux disease. Helicobacter 16: 255-265.

Rajendra S. 2011. Barrett's oesophagus in Asians - are ethnic differences due to genes or the environment? J. Intern. Med. 270: 421-427. Robinson D.S., Q. Hamid, S. Ying, A. Tsicopoulos, J. Barkans, A.M. Bentley, C. Corrigan, S.R. Durham and A.B. Kay. 1992. Predominant TH2-like bronchoalveolar T-lymphocyte population in atopic asthma. N. Engl. J. Med. 326: 298-304.

Rothenbacher D., G. Bode, G. Berg, R. Gommel, T. Gonser G. Adler and H. Brenner. 1998. Prevalence and determinants of Helicobacter pylori infection in preschool children: a populationbased study from Germany. Int. J. Epidemiol. 27: 135-141.

Roussos A., N. Philippou, V. Krietsepi, E. Anastasakou, D. Alepopoulou, P. Koursarakos, I. Iliopoulos and K. Gourgoulianis. 2005. Helicobacter pylori seroprevalence in patients with chronic obstructive pulmonary disease. Respir. Med. 99: 279-284.

Salama N., K. Guillemin, T.K. McDaniel, G. Sherlock, L. Tompkins and S. Falkow. 2000. A whole-genome microarray reveals genetic diversity among Helicobacter pylori strains. Proc. Natl. Acad. Sci. USA, 97: 14668-14673.

Segal I., A. Otley, R. Issenman, D. Armstrong, V. Espinosa R. Cawdron, M.G. Morshed and K. Jacobson. 2008. Low prevalence of Helicobacter pylori infection in Canadian children: a crosssectional analysis. Can. J. Gastroenterol. 22: 485-489.

Sharma P. and N. Vakil. 2003. Review article: Helicobacter pylori and reflux disease. Aliment Pharmacol Ther 17: 297-305.

Shiotani A., T. Miyanishi, N. Uedo and H. Iishi. 2005. Helicobacter pylori infection is associated with reduced circulating ghrelin levels independent of body mass index. Helicobacter 10: 373-378.
Sobhani I., A. Bado, C. Vissuzaine, M. Buyse, S. Kermorgant, J. P. Laigneau, S. Attoub, T. Lehy, D. Henin, M. Mignon and others. 2000. Leptin secretion and leptin receptor in the human stomach. Gut 47: 178-183.

Souza R.C. and J.H. Lima. 2009. Helicobacter pylori and gastroesophageal reflux disease: a review of this intriguing relationship. Dis. Esophagus 22: 256-263.

Suto H., Y. Yamazaki, I. Yoshida, A. Yamakawa, M. Ohtani, Y. Ito, M. Kuriyama, T. Kato and T. Azuma. 2009. The effects of Helicobacter pylori eradication on body mass index and dyspeptic symptoms. Digestion 79: 235-242.

Tegtmeyer N., S. Wessler and S. Backert. 2011. Role of the cagpathogenicity island encoded type IV secretion system in Helicobacter pylori pathogenesis. FEBS J. 278: 1190-1202.

Tsuruta O., H. Yokoyama and S. Fujii. 2012. A new crystal lattice structure of Helicobacter pylori neutrophil-activating protein (HP-NAP). Acta Crystallogr. Sect. F. Struct. Biol. Cryst. Commun. 68: $134-140$

Vakil N. and J. Connor. 2005. Helicobacter pylori eradication: equivalence trials and the optimal duration of therapy. Am. J. Gastroenterol. 100: 1702-1703.

Vitor J.M. and F.F. Vale. 2011. Alternative therapies for Helicobacter pylori: probiotics and phytomedicine. FEMS Immunol. Med. Microbiol. 63: 153-164.

Wren A.M., L.J. Seal, M.A. Cohen, A.E. Brynes, G.S. Frost, K.G. Murphy, W.S. Dhillo, M.A. Ghatei and S.R. Bloom. 2001. Ghrelin enhances appetite and increases food intake in humans. J. Clin. Endocrinol. Metab. 86: 5992.

Wu D.C., P.I. Hsu, J.Y. Wu, A.R. Opekun, C.H. Kuo, I.C. Wu, S.S. Wang, A. Chen, W.C. Hung and D.Y. Graham. 2010. Sequential and concomitant therapy with four drugs is equally effective for eradication of $H$. pylori infection. Clin. Gastroenterol. Hepatol. 8: 36-41 e31.

Yaghoobi M., F. Farrokhyar, Y. Yuan and R.H. Hunt. 2010. Is there an increased risk of GERD after Helicobacter pylori eradication?: a meta-analysis. Am. J. Gastroenterol. 105: 1007-1013; quiz 1006, 1014.

Yamaoka Y. 2008. Roles of the plasticity regions of Helicobacter pylori in gastroduodenal pathogenesis. J. Med. Microbiol. 57: 545-553. Yang L., X. Lu, C.W. Nossa, F. Francois, R.M. Peek and Z. Pei. 2009. Inflammation and intestinal metaplasia of the distal esophagus are associated with alterations in the microbiome. Gastroenterology 137: 588-597.

Zhang Y., R. Proenca, M. Maffei, M. Barone, L. Leopold and J.M. Friedman. 1994. Positional cloning of the mouse obese gene and its human homologue. Nature 372: 425-432.

Zou J., J. Dong and X. Yu. 2009. Meta-analysis: Lactobacillus containing quadruple therapy versus standard triple first-line therapy for Helicobacter pylori eradication. Helicobacter 14: 97-107. 